Disponível em

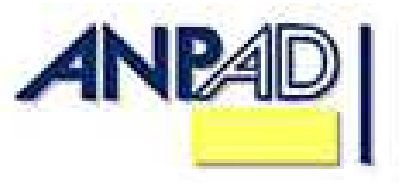
http://www.anpad.org.br/rac

RAC, Rio de Janeiro, v. 16, n. 5, art. 2, pp. 664-683, Set./Out. 2012

(c) EY-NC

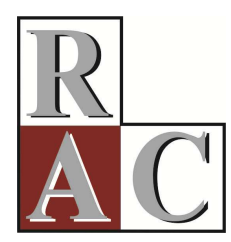

\title{
Os Impactos das Reclamações On-line na Lealdade dos Consumidores: um Estudo Experimental
}

The Impact of Online Complaints on Consumer Loyalty: an Experimental Study

Tatiane Nunes Viana de Almeida*

E-mail: admtatiane@yahoo.com.br Universidade Federal da Bahia - NPGA/UFBA Salvador, BA, Brasil.

Anatália Saraiva Martins Ramos

E-mail: anataliaramos@gmail.com Universidade Federal do Rio Grande do Norte - UFRN Natal, RN, Brasil.

* Endereço: Tatiane Nunes Viana de Almeida Escola de Administração da Universidade Federal da Bahia, Av. Reitor Miguel Calmon, s/n, Vale do Canela, Salvador/BA, 40110-903. 


\title{
Resumo
}

Em um ambiente em constante mutação e com consumidores mais exigentes e informados, a busca de um relacionamento duradouro, por meio da conquista da lealdade, passou a ser o objetivo de inúmeras empresas. Todavia estudos sugerem que essa lealdade pode ser afetada pelos comentários negativos disponíveis na internet. Assim, o objetivo deste estudo é examinar se as reclamações disponíveis no ambiente on-line impactam a lealdade a uma marca de aparelho celular. O método de pesquisa foi o experimental, considerando os antecedentes da lealdade do modelo NCSB Ampliado. A abordagem foi quantitativa e foram utilizados métodos da estatística descritiva, análise fatorial, regressão linear múltipla e teste não paramétrico de Wilcoxon para análise dos dados. Todas as cinco hipóteses propostas foram confirmadas, e os resultados comprovaram que as reclamações on-line podem impactar negativamente a percepção dos consumidores acerca da lealdade, assim como de seus antecedentes. Essas constatações representam um alerta para as empresas atentarem mais ao conteúdo disponível na internet, principalmente em relação às reclamações.

Palavras-chave: lealdade; boca a boca on-line; reclamações on-line; método experimental.

\begin{abstract}
In a constant changing environment characterized by highly informed consumers, the search for long-term relationships through customer loyalty is the goal of many companies. However, studies suggest this loyalty may be affected by negative comments available on the internet. Thus, the aim of this study is to examine if the complaints available in the online environment impact loyalty to a cell phone brand. The research method was experimental, considering the antecedents of loyalty found in the revised NCSB model (Norwegian Customer Satisfaction Barometer). The approach was quantitative, using methods including descriptive statistics, factor analysis, multiple linear regression and non-parametric Wilcoxon test to analyze the data. All five propositions were confirmed. The results showed that complaints available the web may negatively impact consumer perception as it concerns loyalty, as well as its antecedents. These substantiations represent a warning, so that companies can be more attentive to content available on the internet, especially any related to complaints.
\end{abstract}

Key words: loyalty; electronic word of mouth; online complaints; experimental study. 


\section{Introdução}

Em um ambiente em constante mutação, evolução tecnológica, competitividade no mercado e consumidores mais exigentes e informados, a busca de um relacionamento duradouro passou a ser o objetivo das empresas. Esse relacionamento ao longo prazo depende, em muitos casos, da conquista da lealdade dos consumidores (Morgan \& Hunt, 1994), compreendida como um intenso comprometimento em recomprar ou utilizar novamente um produto ou serviço no futuro (Oliver, 1999). Todavia alguns autores (e.g. Cho, Im, Hiltz, \& Fjermestad, 2002; Lee \& Lee, 2006) sugerem que essa lealdade pode ser afetada pelas reclamações disponíveis no ambiente on-line.

A comunicação e a interação social são características inerentes dos seres humanos. Os consumidores têm utilizado cada vez mais a internet como meio para externar frustrações, reclamações ou elogios a empresas e marcas (Vaz, 2008). Por exemplo, um dos segmentos mais reclamados na internet é o de telefonia móvel e celular (Reclame Aqui, n.d.).

Outros aspectos a considerar são no sentido de que: (a) o ambiente on-line tem se destacado como uma das principais formas utilizadas pelos consumidores para buscar informações para fundamentar sua decisão de compra (Barbosa, 2009); (b) a publicidade veiculada na internet está ganhando cada vez mais força (F/Nazca Saatchi \& Saatchi, 2010), uma vez que as opiniões de consumidores postadas on-line são as formas mais confiáveis de informação (Nielsen, 2012); (c) os consumidores consideram as recomendações de outros quando estão no processo de decisão de compra; e, (d) tendem a ser mais sensíveis às informações negativas, ou seja, as reclamações (Lee \& Lee, 2006).

Tendo em vista este contexto, o objetivo do estudo é examinar se as reclamações disponíveis no ambiente on-line impactam a lealdade a uma marca de aparelho celular, assim como seus antecedentes (confiança, imagem/reputação da marca, comprometimentos afetivo e calculado) através de um estudo experimental.

Como justificativa deste estudo, destaca-se que é um assunto atual e de grande importância para as organizações, tendo em vista que a comunicação boca a boca on-line atinge rapidamente inúmeros consumidores reais ou potenciais, podendo representar uma ameaça ou uma oportunidade de novos negócios. Além disso, espera-se que este estudo contribua para trazer uma reflexão sistemática sobre o impacto das reclamações on-line na lealdade à marca, além de suprir a escassez de reflexões atinentes ao tema, proporcionando benefícios que se revelam em conteúdo e base de ação para os interessados.

Para atingir este objetivo o presente artigo é composto das seguintes partes: fundamentação teórica, modelo e hipóteses de pesquisa, método (incluindo a apresentação do contexto de pesquisa escolhido), análise e discussão dos resultados e considerações finais.

\section{Fundamentação Teórica e Hipóteses}

A seguir, serão referenciadas as bases teóricas para o desenvolvimento desta pesquisa: conceitos relacionados com o comportamento do consumidor, a comunicação boca a boca e a lealdade. As hipóteses e o modelo de pesquisa também serão apresentados nesta seção.

\section{Comportamento do consumidor e a comunicação boca a boca}

Os estudiosos do campo do comportamento do consumidor têm constatado a importância dos grupos de referência como fator de influência na decisão de compra. Em especial, a forma de comunicação boca a boca, compreendida como um diálogo informal entre os consumidores sobre as características de uma empresa, marca, produto ou serviço (Ha, 2004). Cabe ressaltar que a 
comunicação boca a boca pode ser positiva (como elogios) ou negativa (como reclamações). A reclamação on-line, foco do presente estudo, é uma das formas utilizadas pelo consumidor para expressar sua insatisfação com uma situação de compra (Santos, 2001), com capacidade de afetar inúmeros indivíduos e causar grandes danos às empresas (Ha, 2004; Lee \& Lee, 2006). Mas, além dos fatores que influenciam o comportamento de compra dos indivíduos, a compreensão sobre como ocorrem as decisões de compra também se mostra relevante.

$\mathrm{Na}$ fase de busca de informações, os indivíduos podem recorrer à busca interna (experiências anteriores) ou à externa (por exemplo, o uso da internet). Trata-se de uma etapa importante, na qual serão levantadas informações que darão suporte à decisão de compra. Com relação à fase de avaliação de alternativas, em geral, os consumidores atribuem importância à opinião dos outros (De Valck, 2005). Segundo Lee e Lee (2006), estudos têm indicado que as reclamações podem causar desastrosos resultados, pois os clientes são muito mais sensíveis a esse tipo de informação.

O boca a boca ainda é um dos instrumentos de divulgação mais fortes, tendo em vista que transmite a credibilidade do seu multiplicador. Tal comunicação verbal exerce "um impacto extremamente forte no comportamento de compra do consumidor" (Mowen \& Minor, 2003, p. 279). Complementando, Ha (2004) afirma que pesquisas têm sustentado a alegação que o boca a boca é mais influente no comportamento do consumidor do que as ações controladas pelas empresas (tais como propagandas).

As constatações mencionadas anteriormente também foram verificadas em algumas pesquisas nacionais (e.g. Cunha, 2007; Scaraboto, 2006; Sperb, 2009). Tais estudos confirmaram que a comunicação boca a boca, realizada através de comunidades virtuais, influencia no processo de decisão dos consumidores. Ratificando a afirmação de Ha (2004), Sperb (2009) concluiu que os comentários sobre experiências de consumo e opiniões de consumidores comuns são considerados mais confiáveis do que a mídia em geral.

Dellarocas (2003) afirma que o boca a boca, mecanismo mais antigo da sociedade humana, está adquirindo um novo significado através das propriedades únicas da internet. O que torna diferente o boca a boca on-line do boca a boca do passado é a combinação (a) da sua escala sem precedentes, (b) da capacidade de controle e acompanhamento mais preciso dos criadores e (c) dos novos desafios introduzidos pelas propriedades da interação on-line, como a natureza volátil das identidades. Assim sendo, conforme destacam Ward e Ostrom (2006), com o advento da internet, os consumidores que já podem manifestar sua insatisfação com uma empresa ou com os membros da sua família, amigos ou conhecidos, estão relatando suas queixas para inúmeras pessoas de forma fácil e barata.

$\mathrm{O}$ advento da internet tornou ainda mais difícil manter a reputação ou a imagem de uma marca, tendo em vista que o consumidor pode ter acesso a inúmeras informações que, há algum tempo, as empresas não disponibilizariam. Assim, alguns estudiosos acreditam que as marcas se tornaram menos importantes na era digital (Rowley, 2004). No entanto, para Jamil (2001), as marcas ainda são válidas, desde que as empresas estejam atentas às mudanças que vêm ocorrendo de forma muito dinâmica no comportamento do consumidor.

Por isso, as empresas precisam criar novas formas para utilizar o ambiente virtual no intuito de agregar valor à marca e, principalmente, minimizar os impactos trazidos pelas reclamações on-line. A construção e manutenção de uma marca forte são enormes desafios e essenciais para adquirir e manter a lealdade dos consumidores.

\section{Lealdade}

Espartel e Rossi (2006) explanam que, desde a década de 1960, a academia tem examinado modelos que relacionam o construto lealdade com a performance de mercado, uma vez que se trata de um componente crucial na geração de lucros. Complementando, Dick e Basu (1994) explicam que a lealdade representa uma importante base para desenvolver uma vantagem competitiva sustentável, 
porém, devido à acirrada concorrência e volatilidade do mercado, sua gestão tornou-se um desafio para as empresas.

No entanto, conquanto a importância da lealdade à marca, o conceito não está claramente definido (Lau \& Lee, 1999), existindo, na literatura, inúmeras definições para este construto (Oliver, 1999). Em um estudo com o objetivo de desenvolver um quadro conceitual pertinente a esse conceito, Dick e Basu (1994) constataram que a lealdade é compreendida como a força da relação entre a atitude do indivíduo e a recompra.

Diante das diversas definições para lealdade à marca presentes na literatura, optou-se por utilizar a de Oliver (1999), na qual o construto é definido como um profundo comprometimento em recomprar ou utilizar novamente um produto ou serviço preferido consistentemente no futuro, causando, portanto, repetição de compras de uma mesma marca ou conjunto de marcas, indiferente às influências situacionais e esforços de marketing, que possuam o potencial de causar um comportamento de mudança, de troca.

Para Aaker (1998), trata-se de um item fundamental, pois a lealdade dos consumidores agrega valor à marca de diversas maneiras, destacando-se: redução dos custos de marketing, alavancagem comercial, atração de novos consumidores e tempo maior para resposta aos concorrentes. Atualmente, devido ao aumento da concorrência global, a lealdade representa uma importante base para o desenvolvimento de uma vantagem competitiva sustentável e a sua gestão pode ser considerada um desafio.

Todavia para que o consumidor torne-se (ou mantenha-se) leal à marca deve haver a crença de que o produto e/ou serviço da empresa é (ou continua a ser) a melhor alternativa do mercado (Oliver, 1999). Por esse motivo, acredita-se que eventos negativos (tais como as reclamações disponíveis no ambiente on-line) podem afetar a avaliação do construto lealdade. Logo, propõe-se inicialmente que (H1) haverá uma diferença significativa entre os escores do construto lealdade antes e depois da exposição do indivíduo às reclamações sobre a marca de aparelho celular (tratamento), de modo que sejam maiores antes do tratamento.

Diante da complexidade desse construto, diversos pesquisadores têm desenvolvido e testado inúmeros modelos de lealdade na tentativa de melhor compreender a natureza dos seus direcionadores. Nesta pesquisa, optou-se por adotar parte do proposto por Johnson, Gustafsson, Andreassen, Lervik e Cha (2001), conhecido como modelo norueguês ampliado (NCSB Ampliado), um dos principais índices de satisfação do cliente. Assim, serão considerados somente os antecedentes da lealdade: imagem, comprometimento afetivo e comprometimento calculado. Além disso, será incluído o construto confiança. A justificativa desta inclusão será exposta no tópico seguinte.

\section{Confiança como antecedente da lealdade à marca}

A crescente importância das relações no mercado tem aumentado o interesse no papel da confiança na promoção do relacionamento empresa-cliente (Sirdeshmukh, Singh, \& Sabol, 2002; Wu \& Tsang, 2008), motivo pelo qual foi incluso este construto como antecedente da lealdade. Para Rousseau, Sitkin, Burt e Camerer (1998), "a confiança é um estado psicológico que inclui a intenção de aceitar a vulnerabilidade com base em expectativas positivas sobre as intenções ou comportamentos do outro" (p. 395), sendo necessária tanto para o desenvolvimento de relacionamentos sociais quanto para os comerciais (Wu \& Tsang, 2008). Ratificando essa afirmação, Gundlach e Murphy (1993) explicam que se trata da variável mais aceita como base para interação humana ou relações de troca, ou seja, uma fé de que a outra parte irá cumprir com suas obrigações sem agir oportunisticamente. Apesar da reconhecida importância desse construto nas relações entre a empresa e o consumidor (Santos \& Fernandes, 2008; Sirdeshmukh et al., 2002; Tax, Brown, \& Chandrashekaran, 1998), poucos estudos têm examinado os comportamentos ou práticas que constroem ou empobrecem a confiança (Sirdeshmukh et al., 2002). Segundo Ha (2004), algumas pesquisas realizadas constataram que a comunicação boca a boca atinge a confiança. Assim, propõe-se que (H2) haverá uma diferença significativa entre os escores do construto confiança antes e depois da exposição do indivíduo às 
reclamações sobre a marca de aparelho celular (tratamento), de modo que sejam maiores antes do tratamento.

\section{Imagem e reputação da marca como antecedente da lealdade à marca}

No modelo proposto por Johnson et al. (2001), o construto imagem da empresa é considerado um dos direcionadores da lealdade. Os pioneiros no estudo sobre a imagem, Gardner e Levy (1955), verificaram que os consumidores valorizam, além do aspecto físico e tangível, os significados simbólicos das marcas dos produtos que consomem.

“A formação da imagem é um processo subjetivo, único, relacionado à experiência individual e, ao mesmo tempo, somatório de sensações, percepções e inter-relações de atores sociais" (Almeida, 2005 , p. 59). Desta forma, o processo de construção da imagem abrange a relação direta do indivíduos com os produtos ou serviços, o contato com os membros da empresa, as informações transmitidas pela organização, as referências de outras experiências, a influência de opiniões de terceiros, entre outros aspectos. Por sua vez, a reputação refere-se à percepção da marca ao longo do tempo, sendo um conceito mais estável do que a imagem (De Chernatony \& Harris, 2001; Selnes, 1993).

Para Johnson et al. (2001), a imagem pode afetar as intenções comportamentais, tais como a lealdade. Em seu estudo, desenvolvido em quatro diferentes indústrias, Selnes (1993) confirmou que a reputação da marca é um importante antecedente da intenção de lealdade. Outras pesquisas em vários setores (e.g. Pinheiro, 2003; Ramos \& Câmara, 2006) também confirmaram que a imagem influencia a intenção de lealdade dos consumidores.

No entanto, Lau e Lee (1999) ressaltam que os consumidores tendem a confiar e comprar um produto quando existe uma opinião favorável quanto à reputação ou imagem da marca. Dessa forma, acredita-se que uma comunicação negativa sobre uma determinada marca fará com que o consumidor também a avalie de forma negativa. Logo, propõe-se que (H3) haverá uma diferença significativa entre os escores do construto imagem/reputação da marca antes e depois da exposição do indivíduo às reclamações sobre a marca de aparelho celular (tratamento), de modo que sejam maiores antes do tratamento.

\section{Comprometimento afetivo como antecedente da lealdade à marca}

Inicialmente desenvolvido para explicar o comprometimento dos empregados, o conceito também se aplica às relações de consumo (Fullerton, 2003; Johnson, Herrmann, \& Huber, 2006). O comprometimento afetivo é enraizado na identificação, compartilhamento de valores, dedicação e semelhança (Fullerton, 2003), sendo afetado diretamente pelo grau de interação pessoal entre o consumidor e a empresa e como a empresa gerencia a conta do cliente ao longo do tempo (Bendapudi \& Leone, 2002 como citado em Johnson et al., 2006). Para Johnson, Herrmann e Huber (2006), o comprometimento afetivo é mais quente ou mais emocional, relacionado com o grau ao qual um cliente se identifica e é pessoalmente envolvido com a empresa.

Logo, o construto comprometimento afetivo tem sido utilizado para ajudar a explicar a variação na lealdade, tendo em vista que essa variável é construída sobre o apego emocional à empresa (Fullerton, 2003). Vários estudos (e.g. Johnson. Gustafsson, Andreassen, Lervik, \& Cha, 2001; Johnson et al., 2006; Morgan \& Hunt, 1994; Pinheiro, 2003) confirmaram a relação positiva e significativa entre este construto e a lealdade.

Todavia, partindo do pressuposto de Lee e Lee (2006) - de que os clientes são muito mais sensíveis às informações negativas - acredita-se que a exposição a comentários negativos poderá afetar o comprometimento afetivo dos consumidores em relação à empresa, logo, sugere-se que (H4) haverá uma diferença significativa entre os escores do construto comprometimento afetivo antes e depois da exposição do indivíduo às reclamações sobre a marca de aparelho celular (tratamento), de modo que sejam maiores antes do tratamento. 


\section{Comprometimento calculado como antecedente da lealdade à marca}

A origem do comprometimento calculado, assim como o afetivo, está na área de comportamento organizacional. Esse construto foi desenvolvido como um meio de explicar a medida que os funcionários se sentem vinculados a uma organização. Nas relações de consumo, o comprometimento calculado é "baseado no auto-interesse da relação, [é compreendido] como o grau no qual o membro é psicologicamente ligado à organização com base nos custos percebidos (econômico, social e relacionado ao status) associados a deixar a organização" (Gruen et al., 2000 como citado em Vieira \& Slongo, 2008, p. 1001). Para Johnson et al. (2001), o comprometimento calculado é frio ou racional, baseado em aspectos econômicos. Alguns estudos (e.g. Ramos \& Câmara, 2006) têm confirmado um relacionamento positivo entre o comprometimento calculado e a lealdade do consumidor.

Mas, diante da carência de estudos que buscam esclarecer os fatores que afetam o comprometimento dos clientes e partindo novamente do pressuposto de Lee e Lee (2006) descrito anteriormente, espera-se que a exposição às reclamações afete o comprometimento calculado, uma vez que este construto está fundamentado em aspectos econômicos.

Assim sendo, ao se deparar com um comentário negativo, o consumidor poderá ter receio de ter futuros prejuízos ao manter o relacionamento com a marca. Logo, sugere-se que (H5) haverá uma diferença significativa entre os escores do construto comprometimento calculado antes e depois da exposição do indivíduo às reclamações sobre a marca de aparelho celular (tratamento), de modo que sejam maiores antes do tratamento.

Com base na fundamentação teórica e nas hipóteses estabelecidas, a Figura 1 apresenta o modelo de pesquisa a ser investigado. A ideia central é que a avaliação sobre a reclamação on-line influenciará os aspectos relacionados à lealdade e seus antecedentes. No entanto, para constatar tais suposições, faz-se necessário verificar as relações entre os construtos antes e depois da exposição à reclamação, ou seja, confirmar se as variáveis independentes (confiança, imagem/reputação da marca, comprometimento afetivo e comprometimento calculado) são antecessoras da variável dependente (lealdade), conforme sugerem diversos estudos.

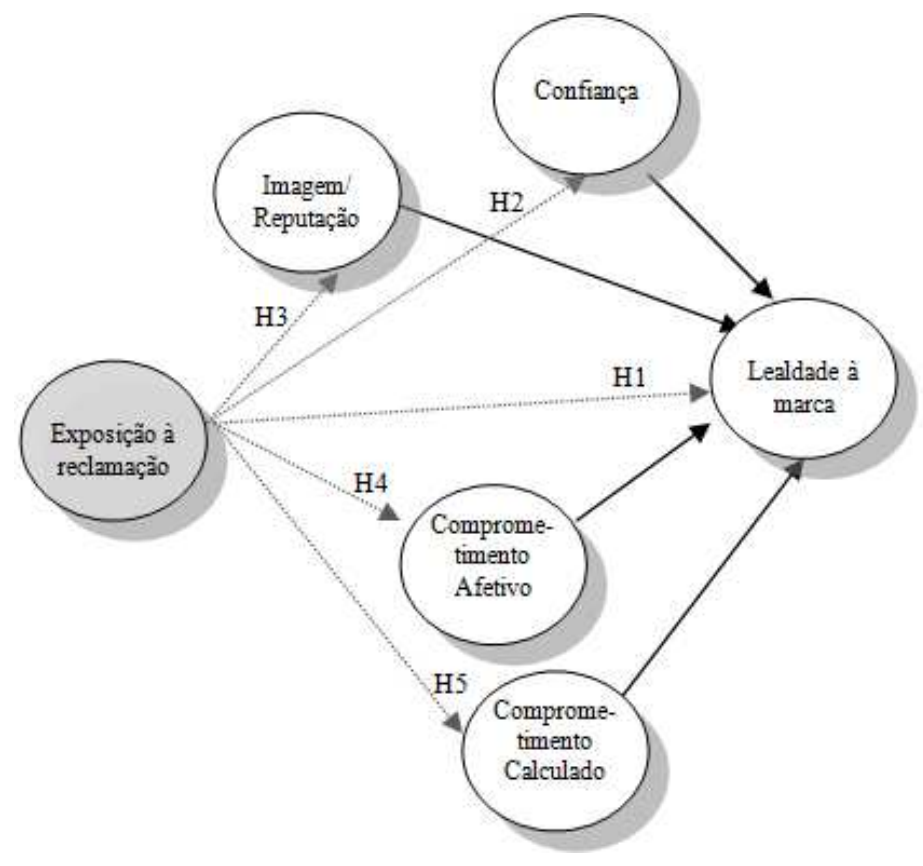

Figura 1. Modelo de Pesquisa.

Fonte: Elaboração dos autores, adaptado de Johnson, M. D., Gustafsson, A., Andreassen, T. W., Lervik, L., \& Cha, J. (2001). The evolution and future of national customer satisfaction index models (p. 231). Journal of Economic Psychology, 22(2), 217-245. doi: 10.1016/S0167-4870(01)00030-7 


\section{Método de Pesquisa}

A presente pesquisa é de concepção longitudinal, tendo em vista que uma amostra fixa de elementos é medida repetidamente (Diggle, Heagerty, Liang, \& Zenger, 2002; Malhotra, 2001), especificamente, em dois momentos distintos, nos quais é verificada a ocorrência de mudanças na lealdade. Conforme explica Newman (2007), pesquisadores utilizam estudo longitudinal para examinar características de indivíduos em mais de um momento, ou seja, pesquisas longitudinais estão em contraste com estudos transversais, nos quais é realizada uma única medição (Diggle et al., 2002). A pesquisa baseia-se no modelo hipotético dedutivo, podendo ser caracterizada como causal, de natureza quantitativa.

Foi utilizado, no estudo em foco, o método experimental como estratégia de pesquisa, ou seja, foram criadas situações com o intuito de analisar seus efeitos sobre os participantes (Newman, 2007). $\mathrm{O}$ experimento realizado neste estudo pode ser caracterizado como o de laboratório, pois os participantes foram "retirados ... do ambiente em que deveriam ocorrer as influências da variável que se quer manipular", sendo criadas condições artificiais para simular as naturais (Moreira, 2002, p. 14). Considerando o objetivo do estudo, o delineamento escolhido foi o pré-teste/pós-teste de um grupo, ou seja, uma única amostra foi medida duas vezes. Logo, trata-se de um estudo pré-experimental, tendo em vista a ausência de aleatorização dos participantes (Cooper \& Schindler, 2003; Malhotra, 2001; Newman, 2007).

Cabe ressaltar que, com base nas explicações de Cooper e Schindler (2003) e Malhotra (2001), foram traçadas várias estratégias com o objetivo de diminuir ou excluir os efeitos das variáveis que afetam a validade interna (história, comunicação entre os grupos de controle e experimental e mortalidade) e externa (efeito reativo no teste ou efeito interativo de teste e interação da seleção e estímulo experimental) deste estudo. Uma das estratégias adotadas para diminuir o efeito da mortalidade, por exemplo, foi a distribuição de brindes (canetas) e de sorteios de prêmios não monetários (aparelhos MP4). Segundo Malhotra (2001), tal estratégia pode ser utilizada para aumentar $\mathrm{o}$ índice de respostas nas pesquisas.

\section{Contextualização do setor de telefonia móvel e do site Reclame Aqui}

Aparelhos celulares foram escolhidos para este estudo por diversas razões: produto com alta penetração do mercado, facilidade de troca e inovações tecnológicas. No entanto, apesar do aumento de usuários de telefones celulares e dos aparelhos homologados disponíveis no mercado, pesquisas apontam para a insatisfação dos consumidores, conforme assinala o ranking dos segmentos mais reclamados do site Reclame Aqui (n.d.), que coloca a telefonia móvel e celulares na segunda posição, juntamente com a telefonia fixa, voip e pagers.

Por sua vez, o site Reclame Aqui foi escolhido por ser considerado o maior da América Latina em defesa do consumidor, sendo a única ferramenta brasileira que está entre as 10 mais colocadas no que se refere à publicação de depoimentos atinentes à experiência de compra com produtos e serviços (E-LIFE como citado em Lima, 2009). O objetivo principal do site é ser um canal de comunicação entre os clientes e as empresas envolvidos em uma relação de consumo.

\section{Abrangência do estudo}

Para esta pesquisa foram considerados como população os estudantes adultos do curso de Administração da Universidade Federal do Rio Grande do Norte-UFRN. A escolha desses indivíduos baseou-se nos dados da pesquisa sobre o uso das tecnologias da informação e da comunicação no Brasil (Barbosa, 2009), os quais apontam que o grau de instrução com maior índice de posse de telefone celular é de nível superior, seguido do nível médio; e a faixa etária variou entre 16 e 24 anos e 25 a 34 anos. Logo, acredita-se que a população selecionada se aproxima dos verdadeiros consumidores de tal produto. 
Para atender aos objetivos da pesquisa, a população estudada correspondeu a 902 alunos que atualmente possuem matrícula ativa no curso, segundo informação repassada pela Secretaria do Curso de Graduação em Administração da UFRN (Sistema Integrado de Gestão de Atividades Acadêmicas [Sigaa], n.d.). A seleção da amostra foi obtida através da amostragem não probabilística por julgamento, contabilizando um total de 242 questionários válidos. Ressalta-se que houve uma perda de dados de 19,03\% neste estudo, ou seja, 67 indivíduos participaram somente da primeira etapa da pesquisa, sendo excluídos da análise.

\section{Operacionalização das principais variáveis e instrumento de coleta}

Para a mensuração das variáveis optou-se por utilizar uma escala do tipo Likert de 10 pontos, variando de discordo totalmente a concordo totalmente, retirada de estudos que examinaram as variáveis que interferem no desenvolvimento da lealdade. Na Tabela 1, são apresentados os construtos, assim como a descrição e origem de cada variável.

Tabela 1

Operacionalização dos Construtos

\begin{tabular}{|c|c|c|}
\hline Construto & Variáveis/Itens & Principais Referências \\
\hline \multirow[t]{4}{*}{$\begin{array}{l}\text { Confiança } \\
\text { (CONF) }\end{array}$} & $\begin{array}{l}\text { CONF1- Eu sinto que minha marca de } \\
\text { aparelho celular é confiável. }\end{array}$ & $\begin{array}{l}\text { Harris e Goode (2004); Santos (2001); Santos e } \\
\text { Fernandes (2008); Sirdeshmukh et al. (2002) }\end{array}$ \\
\hline & $\begin{array}{l}\text { CONF2- Eu sinto que a minha marca de } \\
\text { aparelho celular é competente. }\end{array}$ & $\begin{array}{l}\text { Santos (2001); Santos e Fernandes (2008); } \\
\text { Sirdeshmukh et al. (2002) }\end{array}$ \\
\hline & $\begin{array}{l}\text { CONF3- Eu sinto que a minha marca de } \\
\text { aparelho celular tem integridade. }\end{array}$ & $\begin{array}{l}\text { Santos (2001); Santos e Fernandes (2008); } \\
\text { Sirdeshmukh et al. (2002) }\end{array}$ \\
\hline & $\begin{array}{l}\text { CONF4- Acredito que a minha marca de } \\
\text { aparelho celular está verdadeiramente } \\
\text { empenhada na satisfação dos seus clientes. }\end{array}$ & Harris e Goode (2004) \\
\hline \multirow{3}{*}{$\begin{array}{l}\text { Reputação/ } \\
\text { Imagem da } \\
\text { Marca } \\
\text { (RIMA) }\end{array}$} & $\begin{array}{l}\text { RIMA1- Acredito que a minha marca de } \\
\text { aparelho celular tem uma reputação/imagem } \\
\text { positiva. }\end{array}$ & De Chernatony e Harris (2001) \\
\hline & $\begin{array}{l}\text { RIMA2- A reputação/imagem da minha } \\
\text { marca de aparelho celular é melhor do que a } \\
\text { de seus concorrentes. }\end{array}$ & Johnson et al. (2001); Selnes (1993) \\
\hline & $\begin{array}{l}\text { RIMA3- A reputação/imagem da minha } \\
\text { marca de aparelho celular entre meus colegas } \\
\text { e familiares é positiva. }\end{array}$ & Johnson et al. (2001); Selnes (1993) \\
\hline \multirow{2}{*}{$\begin{array}{l}\text { Comprometi- } \\
\text { mento Afetivo } \\
\text { (COMAF) }\end{array}$} & $\begin{array}{l}\text { COMAF1- Tenho prazer em ter um aparelho } \\
\text { celular desta marca. }\end{array}$ & Johnson et al. (2001) \\
\hline & $\begin{array}{l}\text { COMAF2- Se eu ganhasse de presente, } \\
\text { usaria uma camiseta com o nome ou marca } \\
\text { do meu aparelho celular. }\end{array}$ & Pinheiro (2003); Ramos e Câmara (2006) \\
\hline \multirow{2}{*}{$\begin{array}{l}\text { Comprometi- } \\
\text { mento } \\
\text { Calculado } \\
\text { (COMCA) }\end{array}$} & $\begin{array}{l}\text { COMCA1- Eu teria um grande prejuízo se } \\
\text { tivesse que comprar outra marca de aparelho } \\
\text { celular. }\end{array}$ & Johnson et al. (2001); Pinheiro (2003) \\
\hline & $\begin{array}{l}\text { COMCA2- Economicamente compensa } \\
\text { possuir um aparelho celular desta marca. }\end{array}$ & Johnson et al. (2001); Pinheiro (2003) \\
\hline
\end{tabular}


Tabela 1 (continuação)

\begin{tabular}{|c|c|c|}
\hline Construto & Variáveis/Itens & Principais Referências \\
\hline \multirow[t]{3}{*}{$\begin{array}{l}\text { Lealdade } \\
\text { (boca-a-boca) } \\
\text { (LEALB) }\end{array}$} & $\begin{array}{l}\text { LEALB1- Eu recomendaria os aparelhos } \\
\text { celulares desta marca para outras pessoas, } \\
\text { como amigos, vizinhos e parentes. }\end{array}$ & $\begin{array}{l}\text { De Chernatony e Harris (2001); Johnson et } \\
\text { al. (2006); Santos (2001); Santos e } \\
\text { Fernandes (2008); Selnes (1993); } \\
\text { Sirdeshmukh et al. (2002); }\end{array}$ \\
\hline & $\begin{array}{l}\text { LEALB2- Eu recomendaria esta marca de } \\
\text { aparelho celular para alguém que me pedisse } \\
\text { um conselho. }\end{array}$ & Zeithaml, Berry e Parasuraman (1996) \\
\hline & $\begin{array}{l}\text { LEALB3- Eu direi coisas positivas sobre esta } \\
\text { marca de aparelho celular para outras } \\
\text { pessoas. }\end{array}$ & $\begin{array}{l}\text { Lau e Lee (1999); Santos (2001); Santos e } \\
\text { Fernandes (2008) }\end{array}$ \\
\hline \multirow[t]{4}{*}{$\begin{array}{l}\text { Lealdade } \\
\text { (Recompra) } \\
\text { (LEALR) }\end{array}$} & $\begin{array}{l}\text { LEALR1- Eu considerarei esta marca de } \\
\text { aparelho celular como minha primeira opção } \\
\text { de compra deste tipo de produto. }\end{array}$ & $\begin{array}{l}\text { Santos (2001); Santos e Fernandes (2008); } \\
\text { Zeithaml et al. (1996) }\end{array}$ \\
\hline & $\begin{array}{l}\text { LEALR2- É provável que eu compre outros } \\
\text { aparelhos celulares desta marca novamente. }\end{array}$ & $\begin{array}{l}\text { De Chernatony e Harris (2001); Santos } \\
\text { (2001); Selnes (1993); Sirdeshmukh et al. } \\
(2002)\end{array}$ \\
\hline & $\begin{array}{l}\text { LEALR3- Eu quero continuar a comprar os } \\
\text { aparelhos celulares desta marca. }\end{array}$ & Tax et al. (1998) \\
\hline & $\begin{array}{l}\text { LEALR4- Se eu perdesse meu aparelho } \\
\text { celular, eu compraria outro da mesma marca } \\
\text { novamente. }\end{array}$ & Johnson et al. (2006) \\
\hline
\end{tabular}

\section{Instrumento de coleta de dados}

Foram aplicados dois questionários estruturados e não disfarçados com perguntas sobre o perfil, experiência anterior e satisfação, avaliação e impressão geral sobre o aparelho celular, comprometimento com a marca, intenção de lealdade e dados sociodemográficos. Um instrumento foi aplicado no primeiro momento da pesquisa e o segundo foi aplicado após uma semana, depois da exposição ao tratamento no grupo experimental. Além disso, foi confeccionada uma folha de tratamento contendo as instruções iniciais; a situação (simulação de um episódio que exigia dos respondentes uma busca de informações na internet); três reclamações retiradas do site Reclame Aqui, previamente selecionadas e avaliadas por pesquisadores do Programa de Pós-Graduação em Administração da UFRN; e, as instruções finais. Cabe ressaltar que as reclamações foram exatamente iguais para todos os participantes, exceto no tocante à marca do aparelho celular. Ou seja, cada participante leu a reclamação pensando que se tratava de uma queixa real sobre sua marca atual.

\section{Coleta de dados}

Considerando-se o tempo e os recursos disponíveis para a realização da pesquisa, a coleta de dados foi realizada no setor I do campus central da UFRN. E, com base no delineamento escolhido (pré-teste/pós-teste de um grupo), a pesquisa foi desenvolvida em três etapas: (1) a sensibilização e convocação dos alunos que fizeram parte da amostra escolhida; (2) a primeira coleta de dados (aplicação do questionário 1), realizada nos dias 09 (noite) e 10 (manhã) de novembro de 2009; e, (3) a exposição ao tratamento (leitura da folha de tratamento) e a segunda coleta de dados (aplicação do questionário 2), realizada com intervalo de 1 (uma) semana, especificamente nos dias 16 (noite) e 17 (manhã) de novembro de 2009. Nessa coleta de dados, contou-se com o auxílio de pesquisadores devidamente treinados para a realização deste estudo experimental. 


\section{Análise dos dados}

Os dados foram analisados com o auxílio do pacote estatístico SPSS®, versão 15.0. Em primeiro lugar, foram feitas as análises descritivas da amostra. Em seguida, executaram-se as análises fatoriais para a validação dos construtos e análise de regressão linear múltipla para confirmar os construtos antecessores da lealdade.

Para a prova de comparação dos tratamentos antes e depois da exposição às reclamações, foi empregado o teste não paramétrico de Wilcoxon para amostras relacionadas, uma alternativa para o teste $t$ (Malhotra, 2001), tendo em vista que os dados não apresentaram uma distribuição normal. O teste de postos com sinais de Wilcoxon para pares conjugados é um importante teste não paramétrico para estudar as diferenças na posição de amostras emparelhadas, no qual tais diferenças são analisadas levando em consideração a magnitude das diferenças (Malhotra, 2001; Siegel, 1975).

\section{Análise e Discussão dos Resultados}

Inicialmente, será apresentada a caracterização da amostra. Em seguida, será feita a avaliação das escalas, a confirmação dos antecessores da lealdade e o teste das hipóteses.

\section{Caracterização da amostra e perfil do consumidor}

Os 242 participantes possuem aparelho celular, sendo que a maior parte $(41,3 \%)$ mudou de aparelho celular nos últimos 12 meses. Em relação à faixa etária, a maioria $(84,7 \%)$ tem até 25 anos, seguida de $8,7 \%$ com idade entre 26 a 30 anos, legitimando a amostra selecionada, pois, de acordo com os dados da pesquisa sobre o uso das tecnologias da informação e da comunicação no Brasil (Barbosa, 2009), a faixa etária com maior índice de posse de aparelho celular variou entre 16 e 24 anos e 25 a 34 anos. Mais da metade da amostra é do sexo masculino (58,3\%), solteira (88\%) e com renda familiar mensal com maiores percentuais nas faixas de $\mathrm{R} \$ 1.500,01$ a $\mathrm{R} \$ 3.000,00(30,2 \%)$; de $\mathrm{R} \$ 3.000,01$ a $\mathrm{R} \$ 6.000,00$ (26,0\%); e de $\mathrm{R} \$ 6.000,01$ a $\mathrm{R} \$ 12.000,00(21,9 \%)$.

$\mathrm{Na}$ segunda etapa da pesquisa, em uma escala de 1 a 10, a média da surpresa dos participantes em relação à reclamação de outro consumidor sobre sua marca de aparelho celular foi de $6,44(\mathrm{dp}=$ $2,71)$, sendo que mais da metade $(52,5 \%)$ já tinha tomado ciência de outras reclamações. A média da avaliação dos pesquisados sobre a empresa, em uma escala de 1 a 10 , no primeiro momento da pesquisa, foi de 8,21 ( $\mathrm{dp}=6,29)$, sendo que, após a leitura das reclamações, a média obtida foi de 5,73 $(\mathrm{dp}=2,28)$, sugerindo que o tratamento afetou a percepção dos pesquisados em relação a esse quesito. Por fim, somente 17,4\% dos participantes já conhecia o site Reclame Aqui.

\section{Avaliação das escalas}

A partir das recomendações de Hair, Black, Babin, Anderson e Tatham (2009), a dimensionalidade e a confiabilidade das escalas foram testadas, suportando a inclusão de todos os construtos no modelo de pesquisa, tendo em vista que: (a) as cargas fatoriais dos indicadores nos fatores correspondentes foram grandes e significativas; (b) a medida de adequação da amostra (KMO) foi acima de 0,50; (c) o teste de esfericidade de Bartlett foi significativo, indicando que existem correlações suficientes entre as variáveis (sig. $<0,05$ ); (d) a variância explicada esteve acima do aconselhado na literatura (>60\%); e (e) a confiabilidade, verificada através do Alpha de Cronbach, ofereceu valores superiores a 0,70 , com exceção do construto comprometimento afetivo, que ficou em torno de 0,60 , ainda dentro dos limites para pesquisa acadêmica. No mais, os escores fatoriais de cada construto foram transformados, ou seja, foram distribuídos no intervalo de 1 a 10. 


\section{Confirmação dos construtos antecessores da lealdade}

Conforme mencionado anteriormente, o modelo de pesquisa foi elaborado com quatro proeminentes direcionadores da lealdade: confiança, imagem/reputação da marca, comprometimento afetivo e comprometimento calculado. No entanto, antes de realizar o teste das hipóteses, faz-se necessário confirmar se tais construtos são realmente antecessores da lealdade no grupo pesquisado, nos dois momentos da pesquisa.

Assim sendo, antes do início dos testes, foi verificada a qualidade do banco de dados com o objetivo de identificar os dados perdidos e outliers e verificar a relação entre as variáveis, como a normalidade. Embora os dados tenham apontado para uma distribuição não normal, a normalidade dos resíduos permitiu a utilização da análise de regressão múltipla.

Dessa forma, optou-se por utilizar a análise de regressão múltipla (método Enter) para testar o relacionamento entre a lealdade e seus antecedentes. O resultado está descrito na Tabela 2. As variáveis independentes explicam em $77 \%$ a variação da lealdade dos pesquisados em relação à marca de aparelho celular atual, antes da exposição à reclamação. Ressalta-se que, nessa etapa, todos os construtos mostram-se significantes para a formação da lealdade, sendo que o mais relevante foi a imagem/reputação da marca $(\beta=0,288)$.

Tabela 2

Principais Resultados da Análise de Regressão - Antes da Exposição ao Tratamento

\begin{tabular}{lccccccc}
\hline & $\begin{array}{c}\text { Standardized Coefficients } \\
\text { (b) }\end{array}$ & & \multicolumn{2}{c}{ Model Summary } & \multicolumn{2}{c}{$\begin{array}{c}\text { A NOVA } \\
\text { (b) }\end{array}$} \\
\hline Variável & B & Sig. & R & $\begin{array}{c}\text { R } \\
\text { Square }\end{array}$ & $\begin{array}{c}\text { Adjusted } \\
\text { RSquare }\end{array}$ & F & Sig. \\
Confiança & 0,241 & 0,002 & $0,879(\mathrm{a})$ & 0,773 & 0,769 & 202,017 & $0,000(\mathrm{a})$ \\
Imagem/Reputação & 0,288 & 0,000 & & & & & \\
Comp.Afetivo & 0,262 & 0,000 & & & & & \\
Comp.Calculado & 0,226 & 0,000 & & & & & \\
\hline
\end{tabular}

Nota. (a) Predictors: (Constant), CompCalculado_antes, Reputação_antes, CompAfetivo_antes, Confiança_antes, (b) Dependent Variable: Lealdade_antes

A mesma análise foi realizada no segundo momento da pesquisa, com o objetivo de constatar se os construtos continuam significativos para a formação da lealdade no grupo pesquisado, mesmo após a exposição ao tratamento. O resultado está descrito na Tabela 3. As variáveis independentes explicam em $86 \%$ a variação da lealdade dos pesquisados em relação à marca de aparelho celular, depois da exposição à reclamação. Ressalta-se que todos os construtos mostram-se significativos para a formação da lealdade, sendo que o mais relevante foi a confiança $(\beta=0,345)$. 
Tabela 3

Principais Resultados da Análise de Regressão - Depois da Exposição ao Tratamento

\begin{tabular}{lccccccc}
\hline & $\begin{array}{c}\text { Standardized } \\
\text { Coefficients } \\
\text { (b) }\end{array}$ & & & & Model Summary & \multicolumn{2}{c}{$\begin{array}{c}\text { A NOVA } \\
\text { (b) }\end{array}$} \\
\hline Variável & B & Sig. & R & $\begin{array}{c}\text { R } \\
\text { Square }\end{array}$ & $\begin{array}{c}\text { Adjusted } \\
\text { RSquare }\end{array}$ & F & Sig. \\
\hline Confiança & 0,345 & 0,000 & $0,929($ a) & 0,862 & 0,860 & 371,203 & $0,000($ a) \\
Imagem/Reputação & 0,266 & 0,001 & & & & & \\
Comp.Afetivo & 0,209 & 0,000 & & & & & \\
Comp.Calculado & 0,196 & 0,000 & & & & & \\
\hline
\end{tabular}

Nota. (a) Predictors: (Constant), CompCalculado_depois, Reputação_depois, CompAfetivo_depois, Confiança_depois, (b) Dependent Variable: Lealdade_depois

Os resultados descritos nas Tabelas 2 e 3 confirmam as suposições discutidas na seção Lealdade, ou seja, a confiança, imagem/reputação da marca e o comprometimento afetivo e calculado são antecedentes da lealdade. Destaca-se que, no primeiro momento da pesquisa, a imagem/reputação da marca mostrou-se mais importante no desenvolvimento da lealdade. No entanto, após a exposição ao tratamento, a confiança mostrou-se mais relevante. Assim, constata-se que as reclamações on-line afetaram os direcionadores da lealdade.

\section{Teste das hipóteses}

Com a confirmação dos construtos que antecediam a lealdade à marca, descrita no tópico anterior, partiu-se para o teste das hipóteses, ou seja, verificar o impacto das reclamações on-line na lealdade à marca, bem como em seus antecedentes.

A diferença da avaliação do construto lealdade e de seus antecedentes pode ser verificada na Figura 2, através das médias obtidas em cada fase da pesquisa, ou seja, antes e depois da exposição às reclamações.

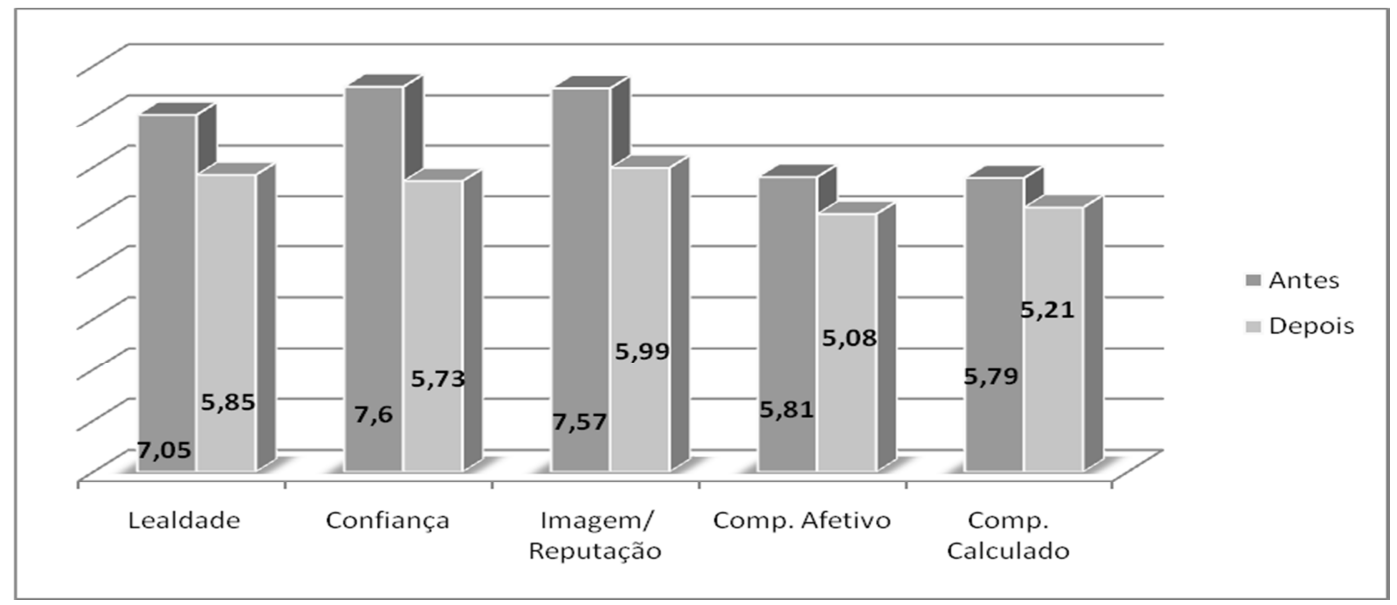

Figura 2. Estatística Descritiva (Média dos Construtos).

Com os dados da estatística descritiva, percebe-se que os pesquisados mostraram-se sensíveis às reclamações contidas no site Reclame Aqui, conforme sugeriram Lee e Lee (2006). A percepção sobre cada construto mostrou-se mais forte no primeiro momento da pesquisa, ou seja, antes da exposição ao tratamento (reclamações). 
Contudo faz-se necessário realizar um teste mais apropriado com o objetivo de constatar se as diferenças sugeridas na Figura 2 são realmente significativas. Para tanto, conforme descrito anteriormente, optou-se pelo teste de Wilcoxon que calcula as diferenças entre os pares de variáveis e os ordena por postos de diferenças absolutas. Em seguida, são somados os postos positivos e negativos que permitem o cálculo da estatístiza $z$. Sob a hipótese nula (de que não existe diferença), $z$ é uma variável normal padronizada com média 0 e variância 1 para grandes amostras (Malhotra, 2001).

As hipóteses de pesquisa sugerem que haverá uma diferença significativa entre os escores dos construtos que compõem o modelo de pesquisa - lealdade (H1), confiança (H2), imagem/reputação da marca (H3), comprometimento afetivo (H4) e comprometimento calculado (H5) - antes e depois da exposição do indivíduo às reclamações sobre a marca de aparelho celular (tratamento), de modo que estes sejam maiores antes do tratamento. Para confirmar essas suposições verifica-se o comportamento dos construtos, apresentado na Tabela 4, ao comparar as respostas dadas antes e depois da exposição ao tratamento.

Tabela 4

Postos do Grupo Experimental

\begin{tabular}{|c|c|c|c|c|}
\hline & & $\mathbf{N}$ & Posto Médio & Soma dos Postos \\
\hline \multirow{4}{*}{$\begin{array}{l}\text { Lealdade_depois- } \\
\text { Lealdade_antes }\end{array}$} & Negative Ranks (Postos Negativos) & 196(a) & 130,21 & 25522,00 \\
\hline & Positive Ranks (Postos Positivos) & $46(b)$ & 84,37 & 3881,00 \\
\hline & Ties (Empates) & $0(\mathrm{c})$ & & \\
\hline & Total & 242 & & \\
\hline \multirow{4}{*}{$\begin{array}{l}\text { Confiança_depois- } \\
\text { Conf._antes }\end{array}$} & Negative Ranks (Postos Negativos) & 204(a) & 136,04 & 27753,00 \\
\hline & Positive Ranks (Postos Positivos) & $38(b)$ & 43,42 & 1650,00 \\
\hline & Ties (Empates) & $0(\mathrm{c})$ & & \\
\hline & Total & 242 & & \\
\hline \multirow{4}{*}{$\begin{array}{l}\text { Imagem/Reput._ } \\
\text { da marca_depois- } \\
\text { Image/Reput. da } \\
\text { marca_antes }\end{array}$} & Negative Ranks (Postos Negativos) & 207(a) & 130,10 & 26931,00 \\
\hline & Positive Ranks (Postos Positivos) & $35(b)$ & 70,63 & 2472,00 \\
\hline & Ties (Empates) & $0(\mathrm{c})$ & & \\
\hline & Total & 242 & & \\
\hline \multirow{4}{*}{$\begin{array}{l}\text { Comprometimen- } \\
\text { to afetivo_depois- } \\
\text { Comprometimen- } \\
\text { to afetivo_antes }\end{array}$} & Negative Ranks (Postos Negativos) & 170(a) & 130,46 & 22178,00 \\
\hline & Positive Ranks (Postos Positivos) & 72(b) & 100,35 & 7225,00 \\
\hline & Ties (Empates) & $0(\mathrm{c})$ & & \\
\hline & Total & 242 & & \\
\hline \multirow{4}{*}{$\begin{array}{l}\text { Comprometimen- } \\
\text { to calcul._depois- } \\
\text { Comprometimen- } \\
\text { to calcul._antes }\end{array}$} & Negative Ranks (Postos Negativos) & 147(a) & 129,74 & 19072,00 \\
\hline & Positive Ranks (Postos Positivos) & $95(b)$ & 108,75 & 10331,00 \\
\hline & Ties (Empates) & $0(\mathrm{c})$ & & \\
\hline & Total & 242 & & \\
\hline
\end{tabular}

Nota. (a) Construto $x \_$depois < Construto $x \_$antes, (b) Construto $x \_$depois > Construto $x \_$antes, (c) Construto $x \_$depois $=$ Construto $x \_$antes.

A Tabela 4 apresenta os postos negativos e positivos verificados nos construtos que compõem o modelo de pesquisa. Como pode ser observado, as diferenças negativas de todos os construtos são maiores que os postos positivos. Ou seja, a maioria dos construtos medidos após a exposição ao tratamento obteve uma avaliação menor do que os mesmos construtos medidos antes da exposição ao tratamento. Também, pode-se observar que não houve nenhum empate ou observações com o mesmo valor para o mesmo construto em ambos os momentos da pesquisa (antes e depois do tratamento). A estatística teste do grupo pesquisado está descrita na Tabela 5. 
Tabela 5

\section{Estatística do Teste do Grupo Experimental}

\begin{tabular}{llrr}
\hline Construto & & & \\
\hline Lealdade & Lealdade_depois - Lealdade_antes & Z & $-9,926(\mathrm{a})$ \\
& & Asymp. Sig. (2-tailed) (b) & 0,000 \\
Confiança & Confiança_depois - Confiança_antes & Z & $-11,973(\mathrm{a})$ \\
& & Asymp. Sig. (2-tailed) (b) & 0,000 \\
Imagem/ & Imagem/reputação da marca_depois - & Z & $-11,218(\mathrm{a})$ \\
Reputação & Imagem/reputação da marca_antes & Asymp. Sig. (2-tailed) (b) & 0,000 \\
Comprometimento & Comprometimento afetivo_depois - & Z & $-6,858(a)$ \\
Afetivo & Comprometimento afetivo_antes & Asymp. Sig. (2-tailed) (b) & 0,000 \\
Comprometimento & Comprometimento calculado_depois - & Z & $-4,009(\mathrm{a})$ \\
Calculado & Comprometimento calculado_antes & Asymp. Sig. (2-tailed) (b) & 0,000 \\
\hline
\end{tabular}

Nota. (a) Baseado em postos positivos, (b) Sig. Exata - Bilateral.

Na Tabela 5, consta a estatística do teste para os construtos que compõem o modelo de pesquisa. Esses números indicam que os cinco contrutos apresentaram menores valores após a exposição às reclamações, sugerindo que o tratamento afetou a opinião dos pesquisados. Além disso, a probabilidade associada à estatística $z$ é inferior a 0,05 em todos os casos, indicando tratar-se de uma diferença significativa. Diante desses resultados, confirmam-se todas as hipóteses de pesquisa.

Logo, os resultados apontam que as reclamações contidas no site Reclame Aqui influenciaram de forma desfavorável a percepção dos pesquisados em relação aos construtos que compõem o modelo de pesquisa, conforme sugeriram estudos anteriores.

No caso da lealdade, Lee e Lee (2006) advertiram que as reclamações podem causar resultados desfavoráveis às empresas, visto que o custo de conquistar novos clientes excede ao custo de manter os clientes atuais.

Em relação à confiança, Ha (2004) alertou em seu estudo que a comunicação boca a boca afeta esse construto e, considerando sua importância para o desenvolvimento de relacionamentos (Wu \& Tsang, 2008), as reclamações on-line podem, por exemplo, levar à redução de vendas, desse modo, prejudicando toda cadeia produtiva.

No que tange à imagem/reputação da marca, os resultados confirmam os achados de Almeida (2005), ou seja, que o processo de construção da imagem abarca, dentre outros aspectos, a relação direta dos indivíduos com a influência de opiniões de terceiros. Além disso, Lau e Lee (1999) também advertem que a construção da reputação está relacionada à opinião dos outros de que a marca é boa e confiável.

Em relação ao comprometimento afetivo, ressalta-se que esse construto é voltado para a parte emocional, assim, capturando a força afetiva do relacionamento que os consumidores têm com uma marca ou empresa e o nível de envolvimento, servindo como uma barreira psicológica para a saída de clientes (Pinheiro, 2003). Por conseguinte, o fato de esse construto ter sido afetado pela exposição às reclamações on-line pode levar o consumidor a questionar sua identificação e envolvimento com a marca ou, ainda, pode levá-lo a desistir de manter um relacionamento com a empresa.

No caso do comprometimento calculado, por estar relacionado a aspectos financeiros, o contato com as reclamações on-line pode ter levado o pesquisado a questionar-se sobre os prejuízos (econômicos, sociais e de status) ao manter o relacionamento com a empresa. Diante dessa situação, o 
consumidor tende a avaliar os custos de mudança, podendo buscar benefícios em empresas concorrentes.

\section{Considerações Finais}

O presente estudo teve como principal objetivo examinar se as reclamações disponíveis no ambiente on-line impactam a lealdade a uma marca de aparelho celular através de um estudo experimental. Dessa forma, para atingir esse objetivo, inicialmente, foi necessário analisar os antecedentes da lealdade do consumidor. Dessa maneira, antes da exposição ao tratamento, os construtos que compõem o modelo de pesquisa explicaram $77 \%$ da variação da lealdade, sendo que a imagem/reputação aparece como principal variável, com peso superior aos demais construtos. Esse resultado corrobora a ideia de que tal construto exerce um forte efeito sobre a lealdade dos consumidores (Selnes, 1993).

Após a exposição ao tratamento, os construtos que compõem o modelo de pesquisa explicaram $86 \%$ da variação da lealdade, sendo que a confiança aparece como principal variável com peso superior aos demais construtos. Esse resultado ratifica a afirmação de Gundlach e Murphy (1993) de que se trata da variável, universalmente, mais aceita como base para as relações de troca e também indica que as reclamações on-line afetaram os direcionadores da lealdade.

Também é possível concluir que as reclamações disponíveis no ambiente on-line, aqui representadas pelas disponíveis no site Reclame Aqui, podem impactar a percepção dos consumidores acerca da lealdade à marca, assim como seus antecedentes (confiança, imagem/reputação da marca, comprometimento afetivo e comprometimento calculado). Essa constatação representa um "alerta" para as empresas atentarem mais ao conteúdo disponível na internet, além de garantir a satisfação dos consumidores em todas as etapas do processo de decisão de compra, evitando, dessa maneira, a divulgação negativa de sua marca.

Nos últimos anos, há cada vez mais a busca de informações. Segundo dados de uma pesquisa realizada pela F/Nazca (2010), até o comércio de rua tem passado pelo ambiente on-line, visto que o número de indivíduos que pesquisam na internet antes de efetuar uma compra tem aumentado nos últimos anos. Em outro levantamento sobre o uso das tecnologias da informação e da comunicação no Brasil (Barbosa, 2009), a busca de informações foi a atividade desenvolvida na internet mais citada pelos pesquisados. E, conforme explica Ha (2004) e como pôde ser constatado neste estudo, o boca a boca exerce um grande impacto no comportamento do consumidor e, consequentemente, na lealdade. Esses valores demonstram para os gestores da área de marketing a necessidade de acompanhar e avaliar as informações transmitidas na internet, ação que pode ser desenvolvida dentro da empresa ou através da contratação de empresas especializadas nesse tipo de serviço.

As escolhas metodológicas fizeram emergir alguns pontos limitantes que precisam ser destacados para que possam ser superados em outros estudos. Dentre os quais, destacam-se: (a) utilização das reclamações impressas, tendo em vista que a percepção dos pesquisados poderia ser diferente se estivessem navegando na internet, (b) amostra não probabilística e composta por estudantes de graduação e (c) utilização de apenas um tipo de produto (celular).

Apesar das limitações inerentes a qualquer pesquisa científica, estudos desta natureza exercem um papel relevante tanto do ponto de vista teórico quanto gerencial. As principais contribuições teóricas estão relacionadas: (a) à utilização de um método (experimental) que é escolhido com pequena frequência na área de ciência social; (b) à adoção de um modelo de pesquisa que pode ser replicado, refinado e consolidado através de outros estudos neste campo de conhecimento; (c) à elaboração e ao teste de hipóteses específicas em relação ao impacto das reclamações on-line na lealdade à marca, dessa forma, proporcionando uma reflexão sistemática sobre o tema, suprindo a 
escassez de estudos; e, (d) além de o resultado poder servir como alicerce para futuras comparações quanto à situação aqui apresentada, inclusive em outros contextos culturais ou sociodemográficos.

A constatação de que as reclamações on-line afetam a percepção dos consumidores acerca da lealdade à marca, assim como de seus antecedentes, tem como principal implicação gerencial a necessidade de que as empresas monitorem todas as reclamações que são divulgadas a seu respeito nos diversos tipos de mídias e redes sociais na internet, pois, dessa forma, poderão minimizar os efeitos negativos. Logo, as empresas precisam adaptar-se ao novo consumidor (informado e consciente de seu papel na relação de consumo) e garantir um relacionamento pós-venda através de monitoramento das insatisfações dos clientes.

Por fim, ressaltam-se a importância da realização de novos estudos sobre o impacto das reclamações e/ou informações disponíveis no ambiente on-line na percepção dos consumidores. Dessa forma, outras pesquisas poderão compreender os resultados aqui apresentados para o mesmo produto, assim como replicá-lo para novos setores, utilizando outros mecanismos disponíveis no ambiente online, tal como Twitter e comunidades virtuais. Ademais, pode-se operacionalizar a exposição ao boca a boca de forma diferente (diretamente na internet, por exemplo), analisar o impacto das reclamações ao longo do tempo ou verificar a influência deste tipo de comunicação em transações que envolvem maior risco, como em serviços ou lançamentos de produtos.

\section{Artigo recebido em 07.10.2011. Aprovado em 17.06.2012.}

\section{Referências}

Aaker, D. A. (1998). Marcas: branding equity gerenciando o valor da marca. São Paulo: Negócio Editora.

Almeida, A. L. C. (2005). A influência da identidade projetada na reputação organizacional (Tese de doutorado). Universidade Federal de Minas Gerais, Belo Horizonte, MG, Brasil.

Barbosa, A. (Coord.). (2009). Pesquisa sobre o uso das tecnologias da informação e da comunicação no Brasil: TIC domicílios e TIC empresas 2008. São Paulo: Comitê Gestor da Internet no Brasil.

Cho, Y., Im I., Hiltz, R., \& Fjermestad, J. (2002, January). An analysis of online customer complaints: implications for web complaint management. Proceedings of the Hawaii International Conference on System Sciences, Waikoloa Village, Hawaii, United States, 35.

Cooper, D., \& Schindler, P. (2003). Métodos de pesquisa em administração (7a ed.). Porto Alegre: Bookman.

Cunha, I. F. (2007). Busca de informações e grupos de referência: um estudo em uma comunidade virtual (Dissertação de mestrado), Universidade Federal de Pernambuco, Recife, PE, Brasil.

De Chernatony, L., \& Harris, F. (2001, October). Measuring the consumer-based equity of financial services brands [Paper Series]. Recuperado de http://www.brandchannel.com/images/papers/Measuringequity.pdf

Dellarocas, C. (2003, October). The digitization of word of mouth: promise and challenges of online feedback mechanisms. Management Science, 49(10), 1407-1424. doi: 10.1287/mnsc.49.10.1407.17308

De Valck, K. (2005). Virtual communities of consumption: networks of consumer knowledge and companionship (Doctoral dissertation), Erasmus Research Institute of Management (ERIM), Erasmus University Rotterdam, Netherlands. 
Dick, A. S., \& Basu, K. (1994). Customer loyalty: toward an integrated conceptual framework. Journal of the Academy of Marketing Science, 22(2), 99-113. doi: 10.1177/0092070394222001

Diggle, P. J., Heagerty, P. J, Liang, K., \& Zeger, S. (2002). Analysis of longitudinal data. New York: Oxford University Press Inc.

Espartel, L. B., \& Rossi, C. A. V. (2006, maio). Um estudo longitudinal da lealdade do cliente e de seus antecedentes. Anais do Encontro de Marketing da Anpad, Rio de Janeiro, RJ, Brasil, 2.

F/Nazca Saatchi \& Saatchi. (2010). Pesquisa F/RADAR - $7 a$ edição. Recuperado de http://www.fnazca.com.br/index.php/2010/11/29/fradar-7a-edicao/

Fullerton, G. (2003). When does commitment lead to loyalty? Journal of Service Research, 5(4), 333344. doi: $10.1177 / 1094670503005004005$

Gardner, B. B., \& Levy, S. J. (1955). The product and the brand. Harvard Business Review, 33, 33-39.

Gundlach, G. T., \& Murphy, P. E. (1993). Ethical and legal foundations of relational marketing exchanges. Journal of Marketing, 57(4), 35-46. doi: 10.2307/1252217

Ha, H. (2004). Factors influencing consumer perceptions of brand trust online. Journal of Product \& Brand Management, 13(5), 329-342. doi: 10.1108/10610420410554412

Hair, J., Black, W. C., Babin, B. J., Anderson, R. E., \& Tatham, R. L. (2009). Análise multivariada de dados (6a ed.). Porto Alegre: Bookman.

Harris, L. C., \& Goode, M. M. H. (2004). The four levels of loyalty and the pivotal role of trust: a study of online service dynamics. Journal of Retailing, 80(2), 139-158. doi: 10.1016/j.jretai.2004.04.002

Jamil, G. L. (2001). Repensando a TI na empresa moderna: atualizando a gestão com a tecnologia da informação. Rio de Janeiro: Axcel Books.

Johnson, M. D., Gustafsson, A., Andreassen, T. W., Lervik, L., \& Cha, J. (2001). The evolution and future of national customer satisfaction index models. Journal of Economic Psychology, 22(2), 217-245. doi: 10.1016/S0167-4870(01)00030-7

Johnson, M. D., Herrmann, A., \& Huber, F. (2006). The evolution of loyalty intentions. Journal of Marketing, 70(2), 122-132. doi: 10.1509/jmkg.70.2.122

Lau, G. T., \& Lee, S. H. (1999). Consumers' trust in a brand and the link to brand loyalty. Journal of Market Focused Management, 4(4), 341-370. doi: 10.1023/A:1009886520142

Lee, S. J., \& Lee, Z. (2006). An experimental study of online complaint management in the online feedback forum. Journal of Organizational Computing and Electronic Commerce, 16(1), 6585. doi: 10.1080/10919390609540291

Lima, A. B. (2009, junho 29). E.Life apresenta estudo sobre perfil da blogosfera brasileira. Recuperado de http://blog.elife.com.br/2009/06/29/elife-apresenta-estudo-sobre-perfil-dablogosfera-brasileira/

Malhotra, N. K. (2001). Pesquisa de marketing: uma orientação aplicada (3a ed.). Porto Alegre: Bookman.

Moreira, D. A. (2002). O método fenomenológico na pesquisa. São Paulo: Thomson Pioneira.

Morgan, R. M., \& Hunt, S. D. (1994, July). The commitment-trust theory of relationship marketing. Journal of Marketing, 58(3), 20-38. doi: 10.2307/1252308 
Mowen, J. C., \& Minor, M. S. (2003). Comportamento do consumidor. São Paulo: Prentice Hall.

Newman, W. L. (2007). Basic of social research: qualitative and quantitative approaches. Boston: Pearson Education.

Nielsen. (2012, April). A Nielsen report global trust in advertising and brand messages. Recuperado de http://www.nielsen.com/content/dam/corporate/us/en/reports-downloads/2012Reports/global-trust-in-advertising-2012.pdf

Oliver, R. L. (1999). Whence consumer loyalty? Journal of Marketing, 63, 33-44. doi: $10.2307 / 1252099$

Pinheiro, I. N. (2003). Gestão de satisfação e fidelidade do cliente: um estudo dos fatores que afetam a satisfação e fidelidade dos compradores de automóveis (Dissertação de mestrado). Universidade Federal do Rio Grande do Norte, Natal, RN, Brasil.

Ramos, R. E. B., \& Câmara, L. L. M. G. (2006, outubro). Fatores da satisfação e fidelidade do cliente: um estudo na construção civil. Anais do Encontro Nacional de Engenharia de Produção, Fortaleza, CE, Brasil, 26.

Reclame Aqui. (n.d). Ranking. Recuperado de http://www.reclameaqui.com.br/ranking/

Rousseau, D. M., Sitkin, S. B., Burt, R. S., \& Camerer, C. (1998). Not so different after all: a crossdiscipline view of trust. Academy of Management Review, 23(3), 393-404. doi: 10.5465/AMR.1998.926617

Rowley, J. (2004). Online branding. Emerald Online Information Review, 28(2),131-138. doi: $10.1108 / 14684520410531637$

Santos, C. P. (2001). Impacto do gerenciamento de reclamações na confiança e lealdade do consumidor, no contexto de trocas relacionais de serviços: construção e teste de um modelo teórico (Tese de doutorado). Universidade Federal do Rio Grande do Sul, Porto Alegre, RS, Brasil.

Santos, C. P., \& Fernandes, D. H. (2008). Antecedents and consequences of consumer trust in the context of service recovery. Brazilian Administration Review, 5(3), 225-244. doi: $10.1590 /$ S1807-76922008000300005

Scaraboto, D. (2006) Comunidades virtuais como grupos de referência nos processos decisórios do consumidor (Dissertação de mestrado). Universidade Federal do Rio Grande do Sul, Porto Alegre, RS, Brasil.

Selnes, F. (1993). An examination of th effect of product performance on brand reputation, satisfaction and loyalty. European Journal of Marketing, 27(9), 19-35. doi: 10.1108/03090569310043179

Siegel, S. (1975). Estatística não-paramétrica para ciências do comportamento. São Paulo: McGrawHill.

Sistema Integrado de Gestão de Atividades Acadêmicas. (n.d.). Lista de alunos ativos no curso. Recuperado de http://www.sigaa.ufrn.br/sigaa/graduacao/busca-discente.jsf

Sirdeshmukh, D., Singh, J., \& Sabol, B. (2002). Consumer trust, value, and loyalty in relational exchanges. Journal of Marketing, 66(1),15-37. doi: 10.1509/jmkg.66.1.15.18449

Sperb, F. C. (2009). Comunidades virtuais: a influência do boca a boca on-line no comportamento dos consumidores (Monografia de graduação). Universidade Federal do Rio Grande do Sul, Porto Alegre, RS, Brasil. 
Tax, S. S., Brown, S. W., \& Chandrashekaran, M. (1998). Customer evaluations of service complaint experiences: implications for relationship marketing. Journal of Marketing, 62(2), 60-76. doi: $10.2307 / 1252161$

Vaz, C. A. (2008). Google marketing: o guia definitivo de marketing digital (2a ed.). São Paulo: Novatec.

Vieira, V. A., \& Slongo, L. A. (2008). Comprometimento e lealdade: dois conceitos ou duas dimensões de um único conceito? Uma resposta a Prado e Santos (2003). Revista de Administração Contemporânea, 12(4), 995-1018. Recuperado de http://www.scielo.br/pdf/rac/v12n4/06.pdf. doi: 10.1590/S1415-65552008000400006

Ward, J. C., \& Ostrom, A. L. (2006). Complaining to the masses: the role of protest framing in customer-created complaint web sites. Journal of Consumer Research, 33(2), 220-230. doi: $10.1086 / 506303$

Wu, J.-J., \& Tsang, A. S. L. (2008). Factors affecting members' trust belief and behaviour intention in virtual communities. Behaviour \& Information Technology, 27(2), 115-125. doi: $10.1080 / 01449290600961910$

Zeithaml, V. A., Berry, L. L., \& Parasuraman, A. (1996). The behavioral consequences of service quality. Journal of Marketing, 60(2), 31-46. doi: 10.2307/1251929 